\title{
FRANCISCO VÉLEZ DE ARCINIEGA EN LA POLÉMICA DE LA COLOQUÍNTIDA
}

\author{
José M. ${ }^{a}$ Valderas \\ Instituto Botánico de Barcelona. \\ Parc de Montjuic, Barcelona.
}

\section{RESUMEN}

Se presenta la edición y estudio de un manuscrito escrito en 1611 por Francisco Vélez de Arciniega sobre el uso de la Coloquíntida (Citrullus colocynthis (L) Schrader). Purgante enérgico, constituían objeto de controversia tanto su interés como la forma de aplicación. Vélez de Arciniega, notable boticario, buen conocedor de la farmacia antigua y moderna, participa en una interesante discusión científica que muestra la modernización del uso de los medicamentos.

\section{SUMMARY}

The paper is the editión and study of manuscript from 1611 by Francisco Vélez de Arciniega about the use of Coloquíntida (Citrullus colocynthis (L) Schrader). Drastic purgative, its interest and instructions for use were under discussion. Vélez de Arciniega, notorius apothecary, good expert on old and modern pharmacy shares and interesting scientific discussion showing the modernization of the use of drugs.

En la renovación de los estudios etnobotánicos, los historiadores de la terapéutica, de la botánica y de la materia médica tienen mucho que decir. Han comenzado a sentirse ya algunas voces ${ }^{1}$. Desde los primeros recetarios, los simples más controvertidos fueron los purgantes, cuya acción drástica acarreaba en no pocas ocasiones la muerte del paciente. De entre los purgantes la coloquíntida, considerado de eficacia media (entre el aceite de castor y la escamonea), conoció una extensísima aplicación, hoy abandonada en los países avanzados. La coloquíntida o tuera (Citrullus colocynthis (L) Schrader.) pertenece a la familia de las Cucurbitaceae. Los dos géneros principales de que dicha familia consta, Citrullus y Cucumis, poseen estrechísimo parecido morfológico, salvo en el fruto (esférico en el primer caso, elipsoide en $\mathrm{Cu}$ cumis) lo que ha inducido frecuentemente a confundirlos en la botánica prelinneana,

1 Holland, Bart K. (ed.) (1996), Prospecting for Drugs in Ancient and Medieval European Texts. A Scientific Approach. Harwood Academic Publishers, Amsterdam. 
con la obscuridad añadida de trocarlos con el cohombrillo amargo (Ecballium elaterium Rich.), otro purgante muy empleado. Los botánicos no han puesto todavía orden en las numerosas variedades en que se presenta la coloquíntida. A lo más, mantienen la separación anterior a la reforma de Schrader entre coloquíntida silvestre, que sería Cucumis colocynthis, y Citrullus colocynthis, la susceptible de ser domesticada, pero no aportan suficientes notas distintivas.

La coloquíntida es una planta trepadora o rastrera con tallos dotados de zarcillos, hojas alternas, ovales, triangulares o acorazonadas en su limbo, pecioladas, partidas en más de la mitad hasta la base. Sus flores, por lo común unisexuales en plantas monoicas o dioicas, actinomórficas, presentan cáliz y corola pentalobulada. El fruto es una calabaza globosa y lisa, con estrías verdes y amarilloblanquecinas, que, en la maduración, se torna amarilla. La pulpa del fruto maduro es esponjosa, ligera, blanca o pajiza y amarga. La tuera vive silvestre en la cuenca mediterránea, en zonas arenosas. (En Arabia Saudí, por ejemplo 2 , medra en los lechos secos de los ríos.) Va enrareciéndose a medida que se extiende, por el este, hasta China y, por el oeste, alcanza Cabo Verde ${ }^{3}$. La pulpa y las semillas son fuertes laxantes, que, tomados en exceso, resultan letales. La pulpa esponjosa de la coloquíntida contiene el glucósido colocintina, al cual se atribuye la actividad farmacológica de esta planta. Las cucurbitacinas triterpenoides de $C$. colocynthis se numeran entre los más amargos y desagradables de los terpenoides vegetales.

La coloquíntida entra en la farmacología desde los albores de la cultura mediterránea. Según leemos en el papiro de Ebers, los egipcios la utilizaban ya como un purgante socorrido ${ }^{4}$. En el Corpus hipocrático aparece en numerosas ocasiones con el nombre usual de kolokynthe agría ${ }^{5}$ y desempeñando siempre una función laxante. Tradición que recogen Dioscórides y Plinio 6 . San Isidoro da fe del conocimiento de la coloquíntida en la España visigoda. Dice en las Etimologías que la «coloquíntida

2 MandaVille, James P. (1990), Flora of Eastern Saudi Arabia. Kegan Paul International, Londres, pp. 123-124.

3 DuARTE, Cristina; MoreinA, Ilidio; Gomes, Samuel e GOMES, Isildo (1996), «Flora das culturas agricolas da ilha de Santiago (Cabo Verde)». García de Orta, serie de Botânica, vol. 13, p. 75.

4 ESTES, J. Worth. (1989), The Medical Skills of Ancient Egypt. Science History Publications, Canton, pp. 100-101; 110-111. MANNICHE, Lise. (1989), An Ancient Egyptian Herbal. British Museum Publications-University of Texas Press, Austin, p. 91.

5 MoISAn, Monique, (1990), Lexique du Vocabulaire Botanique d'Hippocrate. Avec la collaboration de Gilles Maloney et de Denis Grenier. Publication no. 7 De la série «Documents» publiée par le Laboratoire de recherches hippocratiques. Université Laval, p. 48. Véase también RIDDLE, John M. Folk (1987), «Tradition and Folk Medicine: Recognition of Drugs in Classical Antiquity» en Folklore and Folk Medicines. John Scarborough (ed.), American Institute of History of Pharmacy, pp. 33-61).

6 Véanse las voces Colocyntha y Colocynthis en ANDRE, Jacques (1985), Les noms de plantes dans la Rome Antique. Paris, Société d’Edition «Les Belles Lettres», pp. 71-72. El texto dioscorídeo, fundamental para la historia del tema, es el del libro I, 4, 176: WellmanN, M. (ed.) (1907), Pedanii Dioscoridis Anazarbei «De Materia Medica» libri quinque, Berlín (reimp. 1958). 
es una calabaza agreste y amarguísima, que, a la manera de ésta, extiende sus zarcillos por el suelo. Se la llama coloquíntida porque presenta el fruto redondo y echa las hojas como el cohombro» ${ }^{7}$. Muy común entre las tribus predesérticas norteafricanas ${ }^{8}$, la llegada de los árabes a la península Ibérica extendió su aplicación con otros laxantes drásticos.

Aunque conocida al parecer también por otro nombre ${ }^{9}$, la coloquíntida se llama en árabe al murrah y hanzal. De hanzal derivó el castellano alhandal para nombrar la tuera, arabismo común entre los médicos y apotecarios bajomedievales y renacentis$\operatorname{tas}^{10}$. Los árabes dispusieron en su propia lengua de la Materia médica de Dioscórides gracias a la traducción realizada en Bagdad, a mediados del siglo IX, por Istifan b. Basil, versión corregida por Hunayn b. Ishaq. Pero en esta traducción, la mayoría de los nombres de los medicamentos fueron sencillamente transcritos, sin traducirse, ni mucho menos describirse ${ }^{11}$. Esa tarea esclarecedora la llevaría cabo un siglo más tarde el cordobés Abu Dawud Sulayman ibn Hassan («Ibn Yulyul»)12. Contemporáneamente apareció el Kitab al-Tasrif li-man ayiza an al-ta'lif, enciclopedia médica escrita por Abu 1-Qasim Jalaf b. Abbas al-Zahrawi («Abulcasis») (936-1013), en uno de cuyas partes, la denominada Liber Servitoris, en la traducción latina de Simón de Génova y Abraham de Tortosa, dedica un amplio fragmento al modo de preparación

7 «Coloquintis cucurbita agrestis et vehementer amara, quae similiter ut cucurbita per terram flagella tendit. Dicta autem coloquintida quod sit fructu rotundo atque foliis ut cucumis usualis.» Isidorus. Etymolagiarum liber XVII, 9, 32 Comentando este texto Jacques Andrè advierte que procede en parte del De herbis femininis del Pseudo-Dioscórides, 46: Colocinthios (-this Kästner) agria id est cucurbita agrestis, quam Afri gelalam vocant et similiter ut cucumis vel cucurbita per terram flagella tendit.» (Isidore de Séville. Etymologies. Livre XVII. Texte établi, traduit et commenté par Jacques André. París, Société d’Edition «Les Belles Lettres», 1981; p. 181, nota 444. En ese texto del Pseudo-Dioscórides se funda también Riddle para rechazar la afirmación de Pío Font Quer, según la cual la coloquíntida silvestre la introdujeron los árabes. La verdad es que Font no hablaba tanto como historiador, que no lo era, cuanto experto indiscutible en flora norteafricana y botánica médica. Véase RIDDLE, John M. (1981), «PseudoDioscorides’ Ex herbis femininis and Early Medieval Medical Botany», en Journal of the History of Biology, vol. 14, pp. 43-81; en particular, p. 54.

8 KoHLER-ROLLEFSON, Ilse (1996), Traditional Management of Camel Health and Disease in North Africa and India, Ethnoveterinary Research and Development, Edited by Constance M. McCorkle, Evelyn Mathias, and Tjaart W. Schillhorn van Veen, Intermediate Technology Publications, Londres, p. 131.

9 ASIN PALACIOS, Miguel. (1943), Glosario de voces romances, CSIC, Madrid-Granada; p. 372.

10 CarabazA, Julia M. (1994), Plantas en al-Andalus en el siglo XI. Monogr. Jard. Bot. Córdoba I: 5-64.

11 Sobre las traducción y recepción de Dioscórides en el mundo árabe, véase SADEK, M.M. (1983), The Arabic Materia Medica of Dioscorides, Les Éditions du Sphinx, Québec; complementario del trabajo «épico», así lo reconoce, realizado por C. E. Dubler La «Materia Medica» de Dioscórides (Barcelona, 1953-57).

12 DiETRICH, Albert. (1993), Die Ergänzung Ibn Gulgul's zur Materia medica des Dioskurides, Van denhoeck \& Ruprecht, Göttingen. 
de la coloquíntida ${ }^{13}$, y donde se refleja ya los esfuerzos de los médicos por amortiguar los efectos drásticos del purgante con consejos sobre el momento de recolectar su fruto («in fine mensis septembris»), parte aprovechable, dosis y otros detalles que revelan el cuidado extremo que requería su empleo.

La farmacopea árabe alcanza su momento culminante en la figura y en la obra de Ibn al-Beithar, nacido en Málaga a finales del siglo XII, compilador de los trabajos farmacológicos escritos en árabe y autor él mismo de un Comentario a la Materia Médica de Dioscórides (Tafsir Kitab Diyasquridus fi l-adwiya al mufrada) y el Tratado de Simples (Kitab al-Yamí li-mufradat al-adwiya wa-agdiya). Este último, escrito en Damasco entre 1240 y 1248, encierra abundantísima información sobre el empleo de la coloquíntida por los autores que le precedieron ${ }^{14}$, en particular el muy documentado número 714, sobre Handhal ${ }^{15}$. Entre las autoridades que al-Beithar cita se encuentra Mesue.

Mesue cumplirá, en la terapéutica del galenismo arabizado, el papel principal que en los demás terrenos de la medicina desempeñará Avicena. Pero si la figura de éste aparece más o menos delimitada desde muy pronto, el personaje, o personajes, que se esconde tras el Ebenmesue de los medievales está todavía por identificar ${ }^{16}$. Desde la segunda mitad del siglo XIII circulan agavilladas cuatro obras farmacológicas atribuidas a dicho autor de las que, por lo que a la coloquíntida se refiere, importa la primera, De consolatione medicinarum simplicium et correctione operationum earum Canones universales («Reglas generales sobre la rectificación de las medicinas simples y la corrección de sus acciones»), cuya historia y evolución en el Renacimiento ha estudiado. Sieglinde Liebernecht ${ }^{17}$. Se conocen de esta obra 70 manuscritos latinos y 50 ediciones renacentistas (de 1471 a 1635). Se tradujo también al hebreo y al italiano. Comentado, entre otros, por Mondino dei Liuzzi, los humanistas de Ferrara no ahorraron críticas en sus diatribas contra la medicina árabe, corruptora, en su opinión, de la prístina medicina clásica. «Correcciones» que dieron pie a una sonada polémica, en la que participaron en campos enfrentados y de forma destacada

13 ENGESER, Marianne (1986), Der «liber Servitoris» des Abulkasis (936-1013). Ubersetzung, Kommentar und Nachdruck der Textfasung von 1471. Mit einem Geleitwort von Ruldof Schmitz und 6 Abbildungen. Deutscher Apotheker Verlag. Stuttgart.

14 IBN AL--BAYTAR: Traité des Simples. Traduction de Lucien Leclerc. Institut du monde arabe. París, 1877-1883, Reproduction; A.N.R.T. Université de Lille III, s.f. aunque posterior a 1984.

15 714. Handhal, COLOQUINTE/ DiOSCORIDES IV, 175. Id. I, 461-464.

16 JACQuART, Danielle et Troupeau, Gérard (1980), Yuhanna ibn Masawayh (Jean Mesue). Le livre des axiomes médicaux (Aphorismi). Librairie Droz. Genève.

17 LiBerkneCht, Sieglinde (1995), Die Canones des Pseudo-Mesue: Eine mittealterliche Purgantien-Lehre. Prefacio de Fritz Krafft (Quellen und Studien zur Geschichte der Pharmazie, 71.) Wissenschaftliche Verlagsgesellschaft, Stuttgart. 
G. Dupuys y L. Fuchs, y cuyo principal instigador fue Giovanni Manardo ${ }^{18}$. A propósito de la coloquíntida, Manardo se apoya en Dioscórides y en Galeno para rechazar la opinión de Mesue sobre el uso del fruto, al tiempo que le reprocha la interpretación que da de las fuentes en que dice fundarse éste ${ }^{19}$. Este período coincide con la renovación de la botánica, que exige mayor atenimiento a la observación directa de las plantas, renovación instada por la traducción latina de Dioscórides y el descubri-

18 IOANNIS MANARDI medici Ferrariensis, omnium sua tempestate Medicorum, citra controversiam, Doctoris eminentissimi Epistolatum medicinalium Libri XX. Eiusdem in Ioan. Mesue Simplicia et Composita Annotationes et Censurae, omnibus practicae studiosis summe necessaruae. Adiecto Indice latino et Graeco, utroque copiosissimo. Lugduni, Ex officina Godefridi et Marcelli Beringorum fratrum, 1549. Es la edición que he empleado yo. Las cartas de Manardo empezaron a publicarse en 1528. Las Annotationes in Ioannis Meue Simplicia medicamenta: et primum quae sunt a Mesue omissa aparecieron en 1525. Dupuy fue uno de los promotores más enérgicos de la defensa de Mesué contra la crítica de Manardo: PUTEANUS. Guilhelmus. 1537. Joannis Messue... adversum Ioannes Manardum, et Leonardum Fuchsium, aliosque neotericos multos medicos defensio. Lugduni; apud Germanum Rose. Entre los «neotéricos» sobresaldría Symphorien Champier.

19 «De Colocynthida / Colocynthis Graece, Latine agrestis cucurbita dicitur. Eius folia sunt ampla, pilosa.) Ramulos et folia ait Dioscor. per terram steteni, esseque sativo Cucumeri familia, quibusdam diversis seissa. Verum quae non est completa, mala est, et reliqua.) Si haec vera sunt, nunquam erit tutus colocynthis usus: non enim scire possumus, quo solo genita, an in unica planta unica, vel in ea regione unica planta. Et proprie dum iam citrinescit.) Colligendam docet Dioscorid. cum pallidiorem colorem mutari occeperit. Est calidae complexionis et siccae in tertio.) Amaram dicit Galen. non posse tamen id efficere, quod alia faciunt amara, dum bibitur, ob vehementem purgandi vim. Ex quibus verbis monstrat, non ita calidam putasse, ut Mesue: licet sub quo ordine calida esset, non expresserit. Modus rectificandi eius, secundum quod narravit filius Serapionis. et reliqua.) Non hoc preaecipit Serapion, sed Paulus drachmam unam in duobus melicrati cyathis coquens cum Ruta. Et dixit filius Serapion,. oportet ut perveniatur ad ultimum pulverizationis.) Non hoc dixit, sed contrarium, non esse videlicet multum terendam. Paulus autem et Avicenna quem est Mesue secutus, plurimum teri iubent: quoniam (ut inquit Paulus) asperae eius partes interioribus haerentes, ulcera faciunt, quibus nervi compatiuntur. Solutione educit phlegma.) Bilem etiam et strigmenta, dicit Dioscor. Et dixit Dioscorides, non efficit operationem in materiis quae sunt in venis. et reliqua.) Non haec Dioscorides, sed Paulus, cuius haec sunt verba: Interiora Colocynthis nacuant praecipue bilem, et mucos, non a sanguine ut Elleborus et Scammonium, sed a nervis et nervosis membris. Sicut est dolor capitis antiquus.) Paulus, danda his quibus caput est laesum, aut interior vel exterior eius membrana: illam piam matrem, hanc circumossalem vocant: ut vertiginosis, hemicranicis, comitialibus, artonitis, cynico spasmo, asthmaticis, et non nisi recta cervice spirantibus. Descensui aquae ad oculum.) Docet Plinius aquam mulsam in ea coqwui ad dimidias, et sic tussientibus infundi obolis quatuor. Multae eius vires sunt praetermissae, ut quod secundum Paulum valet his, qui circa renes et vesicam patiuntur. Iuxta Plinium in morbo regio utiliter semina insumuntur, et protinus aqua multa: et quod cum oleo si infricetur, spinae, lumborum, et coxacum dolores sanat, et succus eius viridis perfricatus, iuvat coxendice laborantes, autoribus Dioscorid. atque Galen. et quod utilitas clystere pìlae eius iniiciuntur, coxendici, paralysi, et vitiis coli, attestatur Dioscorides. Dosis decem ceratia.) Paulus drachmam integram dare non veretur, quae secundum eum pendit ceratia ondecim. MANARDUS, Ioannes: 1549. Annotationes in Ioannis Mesue Simplicia medicamenta: et primum quae sunt a Mesue omissa. p. 586-587 
miento de la flora europea. Por no ser $C$. colocynthis especie transalpina, los botánicos germanos se apoyan en Dioscórides ${ }^{20}$.

En 1542 Jacobus Sylvius refundió del texto medieval (entonces llamada versio antiqua) en un latín humanista, a la que añadió sus apostillas, junto con sus propias interpretaciones. Pero la edición que adquiriría mayor predicamente fue la de Venecia de 1561 por Vincentius Valgrisius. Esta da, para cada párrafo de los Canones, primero la versión de Silvio y, luego, la versio antiqua seguida por el comentario de Mondino. Aquí encontramos los textos sobre la coloquíntida que van a constituir el objeto central de nuestro trabajo ${ }^{21}$ : la intervención de Francisco Vélez de Arciniega en la polémica de la coloquíntida. Antes, sin embargo, se produce la versión castellana de Andrés Laguna de la Materia médica de Dioscórides, aunque los autores emplean sobre todo la traducción latina de Jean Ruelle. Más tarde aparece la obra botánica de Andrea Cesalpino, donde se ofrece una extensa descripción de la planta que ayuda a reconocer sus notas características, precisas para considerar su aplicación terapéutica. Cesalpino distingue, por ejemplo, una coloquíntida silvestre y otra doméstica, que se manifiesta en el grosor del fruto ${ }^{22}$.

20 HopPE, Brigitte (1969), Das Kräuterbuch des Hieronymus Bock. Anton Hiersemann. Stuttgart; p. 312 .

21 «Troch. colocynthidos in hieram hermetis, et compositiones alias iniiciendi loco colocynthidos. Recipiunt pulpae colocynthidos alba et levis et seminibus purgatae, drach. X. forpicibus incidantur, et fricentur cum unc. 1. olei rosati: fac trochiscos cum muccagine ex tragacanthi, gummi, bdellii, ana, drac. VI. aqua rosarum dies quatuor maceratis, sicca in umbra, tere curiose, et cum eadem muccagine forma rursus trochiscos, et utere. «(p. 148) / A este párrafo sigue la «Sylvii annotatio. Nec hiera hermetis, nec hi trochisci etiam in simplicibus Mesue descripti usurpantur: salubriores tamen, quam ipsis colocynthis sunt.» (p. 148). Texto de la versio antiqua: «Confectio trochiscorum alhandal, qui ponuntur in hiera hermetis, et in aliis confectionibus loco coloquintidae. Accipe pulpae colocynthidis albae et lenis, et mundae a granis (viene un asterisco, que al margen se traduce por unc. X). dra. X. incidantur cum incisorio incisione convenienti, et fricetur cum unc.1. rosati. Deinde accipe tragacanthi, gummi, bdelli, ana drac. VI. infundantur in aqua rosata per dies. IIII. Et conficiantur colocynthide incisa cum glutino eorum, et fiant inde trochisci, et exiccentur in umbra. Deinde iterum terantur contritione bona, etiterum confice cum glutino eorum et fiant trochisci et administrentur. / «Isti trochisci per seipsos non habentur in usu, ingrediuntur tamen hieram hermetis superius dictam, quae in partibus nostris non habetur in usuhabent tamen virtutem solutivam materierum crassarum phlegmaticarum, propter colocynthidem, quae in eis ingreditur.Et dosis esset ad 3. 1. sednon consulo eorum usum.» (p. 148 r.) / «Additio: Isti trochisci sunt in usu sub nomine trochiscorum alandahal, et sub nomine trochiscorum de colocynthide, et secundum intentionem ipsius debent poni in hiera hemetis, et aliis confectionibus loco colocynthidae, et sic generaliter faciunt docti aromatarii. item Mes. hos trochiscos describit supra cap. decolocynthide. Summa medicina est. v. res.» (p. 148 r.) / Mesuae graecorum, ac arabum clarissimi medici Opera quae extant omnia. Venetiis, apud Vincentium Valgrisium, 1562.

22 «Cucurbita sylvestris, fructum fert parvum, et ob amaritudinem ingustabilem: duo eius genera summa proportione respondentia sativis. (Uno silvestre otro cultivado que sería el de mayor tamaño) Quare cum longa convenit, figura Piri, et magnitudine constat, cervice scilicet in gracilitatem producta, colore viridi aliquantum maculoso: haec similiter ut longa, cum perficitur, durescit: nec alium usum praestat, quam parvae ampiullae exemptis seminibus cum fungosa substantia, postquam in arvit: seritur 


\section{EL EMPLEO DE LA COLOQUÍNTIDA EN ESPAÑA A PRINCIPIOS DEL SIGLO XVII.}

La terapéutica de Mesue rige en España hasta finales del siglo XVII. En tan larga pervivencia tuvo mucho que ver Francisco Vélez de Arciniega, uno de los pocos que supo sistematizar las ideas escondidas bajo un magma de recetas y preparaciones dispersas por antidotarios y cánones. Nacido en Casarrubios del Monte (Toledo) en torno a los años cincuenta o sesenta del siglo XVI y fallecido en fecha posterior a 1624, fue Vélez boticario en Toledo, donde llegó a ocupar el cargo de farmacópola del arzobispo Bernardo de Sandoval y Rojas; de allí pasó a Madrid y fue boticario de la corte. Su obra escrita versa sobre aspectos fundamentales y aplicados del arte. Su alarde de erudición, propio del tiempo por otro lado, suele ser en numerosas ocasiones pertinente. Contó entre sus discípulos a Jerónimo de la Fuente Pierola.

La obsesión de Vélez fue redactar una farmacopea general, la primera de haberse cumplido, que sirviera de prontuario para todos los apotecarios españoles. Los libros son, en buena medida, aproximaciones o capítulos de ese compendio. Pese a la importancia de tamaña empresa, no existe ninguna monografía sobre nuestro autor, salvo las entradas de las historias de la farmacia o los repertorios comentados. Lo reconoce así Juan Esteva de Sagrera, autor de un ensayo sobre el Libro de los quadrupedos y serpientes terrestres recebidos en el uso de la medicina y de su preparación, de Francisco Vélez, cuya introducción al mismo resuelve las dudas sobre el elenco real de las obras del boticario toledano ${ }^{23}$. Capítulo central de toda farmacopea del siglo XVI era el relativo a los purgantes. Y en particular, la coloquíntida. La conveniencia de su uso se convirtió en el centro de numerosas disputas a lo largo de esa centuria. En España cobró especial virulencia en los primeros años del XVII a raíz de un enfrentamiento en el que se vio implicado el Colegio de Médicos de Zaragoza.

in viridariis ad parietes convestiendos. Plinius inter Cucurbitas sylvestres Somphon a Graecis appellari scribit: quia inanis digitali crassitudine non nisi saxosis nascens. Quae autem cum genere rotundarum convenit duplex visa est, una colore viridi, magnitudine, quae utramque manuum impleat. Altera minor colore flavo similis Aurantiis Malis, medulla amaritissima: huius folia a caeteris distant: incisa enim sunt ut folia Anguriae, sed longe minora: huius medulla arida et fungosa venditur in officinis inter purgantia medicamenta externa, Coloquintidam vocant: Apud Dioscoridem Colocynthis appellatur: sarmenta, inquit, et folia repentia, divisa, fructum specie mediocris pilae conglomeratum, vehementer amatum, quem legere oportet, cum coeperit in pallidum colorem permutari. Medulla fructus purgatoriam vim habet. Plinius utranque videtur novisse, cum inquit, Colocynthis inter cucurbitas sylvestres vocatur, quae plena, sed minor, quam sativa, utilior, pallida, quando eius sunt medicinae. Herbacea arefacta per se inanit alvum. Mesues quandam tradit lanuginosam, gravem, et duram, asperamque tendentem ad nigredinem, quae mas vocatur, alteram foeminam a medicis receptam: laudat autem crassam, et levem, laxam, et albam ac lenem completae maturitatis, cuius pars interior pulposa, laxa et lenis, et alba vehementis albedinis.» CESALPINUS Andreas, 1583: De Plantis libri XVI. Florentiae: Marescottum. Libro V, cap. 3. p. 198).

23 EsteVA De SAGRERA, Juan. (1977), Comentario al «Libro de los quadrupedos y serpientes terrestres recebidos en el uso de la medicina y de su preparación» de Francisco Vélez de Arciniega», Unifarma X, 484-495. 
Iniciada la polémica apareció en 1603 Pharmacopoea. Decem sectiones eis; qui ipsius artem exercent, descriptiones necnon medicaminum compositorum hoc aevo usitatissimorum admodum necessarias continens: Mesues atque regulas tyronibus hac in arte parum exercitatis Hispanicam in linguam translatas, marginalibus, ac Latinis annotationunculis valde utiles de Francisco Vélez ${ }^{24}$.

La publicación de la Pharmacopea aumentó el prestigio de Vélez, ya plenamente asentado en la corte. Nada tiene, pues, de extraño que en plena crisis del uso de ese purgante drástico, fuera reclamada su opinión autorizada. Desde 1601, Cosme Novella, apotecario de Albarracín y a la sazón Visitador de la Botica del Hospital General, está enfrentado contra el Colegio de Médicos de Zaragoza por el uso corrrecto de la coloquíntida. Novella denunciaba que allí se prescribían la coloquíntida y purgantes fuertes (escamonea, heléboro, hermodáctiles y lapislázuli) solos, diluídos en polvo y fritos en aceite de rosas, en vez de prepararlos rectificados en trociscos, píldoras o tabletas. Como es sabido, en la disputa intervinieron de forma directa o indirecta instituciones de dentro y fuera de Aragón. En un comienzo parece que se impone la tesis de Novella cuando, en 1610, el Consejo Supremo de Aragón obliga a administrar la coloquíntida preparada en trociscos. No se da por satisfecho el Colegio de Médicos, e intrigas y enredos aparte relatados por el propio Novella, logra aquella institución que el Rey mande el uso de la coloquíntida molida sutilísimamente con aceite de rosas.

¿Quién ha podido lograr que nada menos que Felipe III se decantara a favor del Colegio y en contra de su mismo enviado? Si Novella había apelado en pro de su causa a las universidades de Valladolid, Salamanca y Huesca, el Colegio reclama la ayuda de Vélez de Arciniega. Este había cerrado su Pharmacopoea con un capítulo consagrado a la coloquíntida, donde encontramos esbozado el guión que desarrollará más tarde ${ }^{25}$. Para entender no sólo los conceptos y razonamientos que esgrimirá luego, sino también para profundizar en su formación tendremos que sumergirnos en ese tratado de farmacia. Siendo ésta tradicionalmente «ars recte colligendi, eligendi, miscendique medicamina», que él traduce y extiende así: «No es otra cosa el arte del boticario que saber como coger, escoger, preparar, guardar, componer y mezclar bien

24 VeleZ DE ARCINIEGA, Francisco. 1603. Pharmacopoea. Decem sectiones eis; qui ipsius artem exercent, descriptiones necnon medicaminum compositorum hoc aevo usitatissimorum admodum necessarias continens: Mesues atque regulas tyronibus hac in arte parum exercitatis Hispanicam in linguam translatas, marginalibus, ac Latinis annotationunculis valde utiles. Matriti. Typis Michaelis Serrani de Varga.

25 «20. Collocyntidis praeparatio, ut autor est Mesue. R. pulpae colloquintidae albae, et lenis, et mundae a granis unc. X. incidatur cum incisorio incisione convenienti, et fricentur cum unc. $i$. olei rosati. Deinde accipe dragaganti gummu bdelii ana drach, vi. infundantur in aqua rosata per dies quatuor, et conficiatur coloquintida incisa cum glutino eorum, et fiant inde trochisci, ex exiccentur in umbra. Deinde iterum terantur contritione bona, et iterum confice cum glutino eorum, et fiant trochisci, et administrentur. (Pharmacopoea, p. 194v.) 
los medicamentos.» ${ }^{26}$. Tal será el modo de proceder de Vélez: partirá de un texto de una autoridad (aquí, el Canon de Mesue en buena medida) que él explica, amplía o corrige con otros textos del mismo o de otro autor, corroborado con la propia experiencia adquirida en el ejercicio del arte.

Lo primero que le importa será, pues, que el texto escogido sea fiel, no corrompido. En segundo lugar, que la autoridad invocada lo sea en el dominio particular de la cuestión. A propósito de las proporciones en que deben entrar los ingredientes de los fármacos, apela a Arnau de Vilanova; en cuestiones de botánica a Rembert Dodoens ${ }^{27}$. Por lo que concierne a la física farmacológica, es decir, las cualidades de las medicinas -tacto, olor, sabor y color- se apoya en las definiciones aristotélicas. Tales referencias nos evocan un Vélez inmerso en la corriente neoaristotélica médica, que en Italia representa Cesalpino, citado por él, corriente apenas estudiada. En nuestro boticario, sin embargo, manifiesta unos caracteres peculiares, únicos. Por ejemplo, su doctrina resulta menos sistemática y elaborada, aunque más ecléctica, fruto de una lectura enciclopédica no siempre bien asimilada. Es ingente el número de autores antiguos y medievales, árabes sobre todo, que trae a colación. Pero no es menos llamativo su conocimiento de los «modernos»: De la Ruelle, Manardo, Valerius Cordus, Fuchs, Joubert, los «Frelonios», Musa Brasavola, Agricola, Cristóbal de Acosta, Clusius, Fragoso, Dodoens y, sobre todo, los comentaristas del Canon Sylvius y Costa, estos últimos sus preferidos. Comparte con la mayoría de los autores más innovadores que el criterio último de la farmacia, en cuanto ars, reposará en la propia observación: «Va mucho del dezir al hazer; y a esta causa, el que lo quisiere experimentar, como yo lo he hecho» ${ }^{28}$.

Preparación clásica de todos los antidotarios y, por tanto, obligada en la Pharmacopoea, era la de los trociscos de coloquíntida. Debe, pues, empezar por una descripción adecuada del proceso que han de aprender los boticarios. En efecto, tras enunciar los componentes y proporciones según el Canon, prosigue: «Para formar estos trochiscos, y preparar la coloquintida, se tomaran las dichas quantidades, y las gomas despues de quebrantadas se pondrán en una vasija vidriada, y sobre ellas la quantidad suficiente de agua rosada caliente, y se dexaran por quatro días./ La coloquíntida se cortara menudamente con unas tigeras, y embolverase con el dicho mucilago, y formarase en trochiscos. Y aunque dize Mesue, que se ponga en dos vezes, se pondrá en una todo, y se remoleran después de secos, y se tornaran a formar con el mismo mucilago que tienen en si embevido, y harase esto tres o quatro vezes, hasta que se ayan subtilizado muy bien.» ${ }^{29}$.

\footnotetext{
26 Pharmacopoea, Prefacio.

27 «Al leño llaman los griegos (xylé) y es (segun dice Dodoneo) la parte interior rodeada de corteza dura y que se puede hender, asi como cuerpo, o carne de los arboles y frutices.» (Pharmacopoea, p. 98v).

28 Pharmacopoea, Prefacio.

29 Pharmacopoea, p. 195 r. 
Expuesta la preparación, Vélez se hace eco de la polémica desatada en Zaragoza, sin aludirla directamente, avanzando de inmediato su propia opinión: «Estos trochiscos dixo Mesue que entravan en la hiera Hermetis, y en otras composiciones en lugar de la coloquintida. Y por no haber entendido algunos lo que quiso dezir, quieren que se pongan en su lugar en todas las composiciones: mas el intento de Mesue no fue dezir que se pusiessen en las suyas, sino que se ponían en el hiera de Hermes, y en otras composiciones del dicho Hermes» ${ }^{30}$. Para Vélez, cuando en una receta de Mesue se exige coloquíntida, debe emplearse coloquíntida sin sucedáneos, ni preparaciones que la desvirtúen.

Debió de ser muy fundado el razonamiento de Vélez en su informe al Colegio de Médicos de Zaragoza para ganarse la voluntad del monarca. ¿En qué terminos se expresó? En la biblioteca Salvador del Instituto Botánico de Barcelona se conserva, sin catalogar, el manuscrito, o una copia coetánea, de la contestación de Vélez de Arciniega. Está encuadernado en guardas de piel de un manuscrito tardomedieval. Ha perdido los hilos del cosido y parte de ambas guardas, anterior y posterior. Consta de tres cuadernillos de ocho hojas cada uno, sin numerar. De la primera hoja del segundo cuadernillo aparecen incompletas (se han rasgado en parte) las once primeras líneas de ambas páginas, si bien la merma no afecta al contenido central del escrito. Concluye con la fecha de redacción, el dos de enero de 1611 y la firma del autor. Aunque desconocemos la historia seguida por el manuscrito, hay razones externas e internas para certificar la verosimilitud de la autoría de Vélez de Arciniega. El papel, la tinta empleada y la caligrafía son propias de un escritor del primer tercio del XVII. Que lo redactó quien lo firma, Francisco Vélez de Arciniega, está acorde con la trayectoria intelectual de este farmacéutico y, en particular, con su Pharmacopea de 1603. En la biblioteca Salvador del Instituto Botánico de Barcelona se guarda un importante fondo de la farmacia de los siglos XVI y XVII, por lo que tampoco extraña su presencia en ese lugar. El manuscrito no sólo refleja la opinión de Vélez, sino también la posición criticada. Constituye, pues, una óptima muestra de la justificación de los remedios purgantes de la materia farmacéutica vegetal en la España de comienzos del XVII.

\section{ESTRUCTURA DEL MANUSCRITO}

El manuscrito consta de encabezamiento, nudo de la polémica y razonamiento de la solución. Reza así el encabezamiento: «IESUS MARIA- / Informacion hecha por franco Velez de Ar / ciniega boticario del Ilto de Toledo a / peticion del Collegio de los Medicos / y Cirujanos de la Ciudad de Zara- / goça, para el pleyto que tra / ta contra Cosme Novella / acerca del uso que se / deve tener dela / Colocinthida».

\footnotetext{
30 Pharmacopoea, Id.
} 
El nudo de la polémica es si deben ponerse los trociscos de Alhandal en todas las composiciones en que se pide coloquíntida, en las composiciones en que se reclama tal sustitución expresis verbis o sólo en las preparaciones en que se pide coloquíntida preparada $^{31}$. Puesto que se trata de un problema de interpretación, uno de los factores principales que entrarán en la polémica será el análisis de textos. El trasfondo de la cuestión radicaba, sin embargo, en el recelo que empezaba a manifestarse en torno al uso farmacológico del fruto de coloquíntida, dados los efectos drásticos que ese purgante provocaba. Se abría así una brecha crítica, aunque sutil todavía, en el quehacer farmacéutico pegado a los dictados de los recetarios. La polémica giraba, en efecto, en torno a la hermenéutica de un texto del Antidotario de Mesue: «Confectio trochiscorum Alhandal, qui ponuntur in hyera Hermetis, et in aliis confectionibus loce Colocynthidae». Los términos equívocos concernían a la expresión in aliiis ${ }^{32}$. La hiera era un fármaco purgante de la tradición galénica, de la que habla ya el propio Galeno en De sanitate tuenda ${ }^{33}$ y encontramos repetidamente aludida en los autores árabes ${ }^{34}$.

El informe manuscrito de Vélez constituye una aplicación pormenorizada de los principios establecidos en su Pharmacopoea decem sectiones y una extensión del apartado que dedica a la coloquíntida. Tras relatar y glosar preparaciones de distintos autores, cierra la Pharmacopoea con la preparación de la coloquíntida según Mesue: Collocyntidis praeparatio, ut autor est Mesue. R. pulpae colloquintidae albae, et lenis, et mundae a granis unc. X. incidatur cum incisorio incisione convenienti, et fricentur cum unc. i. olei rosati. Deinde accipe dragaganti gummu bdelii ana drach, vi. infundantur in aqua rosata per dies quatuor, et conficiatur coloquintida incisa cum glutino eorum, et fiant inde trochisci, et exiccentur in umbra. Deinde iterum terantur contritione bona, et iterum confice cum glutino eorum, et fiant trochisci, et administrentur. Texto que él mismo traduce abreviadamente con algunas interpolaciones aclaratorias: «Para formar estos trochiscos, y preparar la coloquintida, se tomaran las dichas quantidades, y las gomas despues de quebrantadas se pondran en una vasija vidriada, y sobre ellas la quantidad suficiente de agua rosada caliente, y se dexaran por quatro dias. / La coloquintida se cortará menudamente con unas tigeras, y embolverase con el dicho mucilago, y formarase en trochiscos. Y aunque dize Mesue que se ponga en dos vezes, se pondra en una todo, y se remoleran despues de

31 «Tratasse, y esta puesto en controversia si se / han de poner los trochiscos de Alhandal en to- / das las Compositiones en que se pide Colochin- / tida, ó en solas aquellas en que los auctores / los piden determinadamente por su propio / nombre, ó en que piden Colochyntida prepa- / rada. (Manuscrito, 1r.)

32 «La occasion de esta difficuldad han / sido aquellas palabras que Mes. escrivió en / su antidotario, tratando destos dichos tro-/ chiscos, que son las siguientes. Confectio tro- / chisconum Alhandal, qui ponuntur in hyera/ Hermetis, et in aliis Confecti loce Colocynthi-/ dae. (Manuscrito, 1r).

33 Galenus, De sanitate tuenda, VI 429. Claudii Galeni opera omnia. Editionem curavit D. Carolus Gottlob Kühn. Leipzig 1821-1833. Reimpresión Hildesheim; 1965.

34 Véase, por ejemplo: ENGESER, Marianne (1986), Der «Liber Servitoris» des Abulkasis (936-1013), Quellen und Studien zur Geschichte der Pharmazie, b.37. Deutscher Apotheker Verlag. Stuttgart; pág. 12. 
secos, y se tornaran a formar con el mismo mucilago que tienen en si embevido, y harase esto tres, o quatro vezes, hasta que se ayan subtilizado muy bien» ${ }^{35}$.

Y sin más preámbulo entra en el centro de la controversia: «Estos trochiscos dixo Mesue que entravan en la hiera Hermetis y en otras composiciones en lugar de la coloquintida: y por no aver entendido algunos lo que quiso dezir, quieren que se pongan en su lugar en todas las composiciones: mas el intento de Mesue no fue dezir que se pusiessen en las suyas, sino que se ponian en el hiera de Hermes, y en otras composiciones del dicho Hermes ${ }^{36}$. Las razones en que se fundan son primariamente de exégesis externa, de análisis textual ${ }^{37}$ y contextual ${ }^{38}$. Va desgranando, luego, las formas de entender esa preparación y otras asimiladas. Así, se tomará como simple, no recortada en esas bolas que eran los trociscos, cuando los antidotarios fiables lo exijan $^{39}$. Una tercera razón que aclara el sentido de las palabras de Mesue reside en la naturaleza de la composición farmacológica. Creíase que, en los medicamentos compuestos, un simple corregía, atemperaba o neutralizaba la acción de otro con el que fuera «asociado» 40 .

\footnotetext{
35 Pharmacopoea, $195 \mathrm{r}$
}

36 Id.

37 «Que esto sea verdad, veese de sus palabras que son: Confectio trochiscorum de alalndahal, qui ponuntur in hiera Hermetis, et in aliis confectionibus (scilicet ipsius Hermetis) loco coloquintidae:» (Id.)

38 «y de la dicha hiera y de las pildoras de alandahal que Mesue escrivio en su antidotario de autoridad del dicho Hermes, en las quales en lugar de coloquintida pidio el dicho Hermes trochiscos de alandahal.» (Id.)

39 «De manera que quando en alguna composicion se pide coloquintida, no se han de poner estos trochiscos, sino sola la coloquintida sin preparar. Que no se aya de poner preparada vese de la recepta de la hiera diacoloquintidos que escrivio Mesue. Pues esta escrito en su recepta coloquintidae bonae electae drach. XX Et in loco alio coloquintidae, trochiscorum alandahal ana drach. XXV». (Pharmacopoea, 195r-195v.)

40 «Y si se huvieran de poner en todas las composiciones los trochiscos dichos por coloquintida, no pusiera el otro codice (como dize la recepta) de cada cosa veynte y cinco dracmas, sino cincuenta de lo uno, ò de lo otro. No es necessario echar en los medicamentos compuestos la coloquintida, ni otro algun simple preparado, sino es pidiendole el autor con algún particular intento, porque en los mismos compuestos entran otros que los corrigen. Que esto sea verdad, veese de Cesalpino, el qual dize, que en los compuestos se mezclan simples que corrigen la malicia de los purgantes, y que se ponen en ellos semejantes y contrarios, los semejantes para que unos y otros se ayuden para hazer la purgacion, y los contrarios para que corrijan su malicia. Mudamos (dize el dicho) las facultades de los medicamentos, no solamente con la preparacion, mas tambien con la mistion. Desta verdad que dize, son testigos Galeno c. 31 lib. Quos quibus, etc. Y en el com. 2. in lib. de rat. vict. in morb. acut. y en el cap. 5. lib. 1 de comp. med. perg. Damocrates (como se vee en Mesue) y el propio Mesue, Avicenna c. 9. fen. 4. lib. 1. Placentino de Saliceto c. 2. lib. 5. Jouberto en un tratado que hizo del arte de componer las medicinas y con ellas Bernardo de Senio, y toda la classe Griega y Arabiga de Medicina. De donde se vee que no se ha de poner la coloquintida, scammonea, turbith, agarico, hermodactyles, ni los demas medicamentos simples a estos semejantes corregidos en las composiciones, donde expressamente no los piden corregidos, ò preparados los autores. / Algunos ay que dizen que manda Serapion, que se eche preparada la coloquintida en todas las masas de pildoras, mas no dize sino que quando se hizieren pildoras della para tomar: no se hagan 


\section{CUERPO DEL INFORME}

Adviértese de entrada una leve modificación respecto al nudo de la polémica. En la Pharmacopoea, el in aliis se refiere determinadamente a las composiciones de Hermes, en tanto que en el Informe no lo acota a dicho supuesto autor. Sencillamente, en este in aliis no sustituye a todos (omnibus), como opinan los partidarios del uso de la coloquíntida en trociscos. Sólo debe recurrirse a tales fármacos cuando hablamos de coloquíntida mala, no buena; ésta, como se verá, puede emplearse sutilmente molida con aceite de rosas. Para llegar a tan tajante solución divide su discurso en seis puntos. Primero: averiguar de qué especie de coloquíntida está hablando Mesue. Segundo: si debe prepararse con la trituración sutil. Tercero: si no necesita rectificarse ni, por tanto, asociarse. Cuarto: si conviene prescribirla sólo para las enfermedades graves. Quinto: si es tan drástica en su acción como la de otros purgantes amargos. $Y$ sexto: interpretación del texto de Mesue en coherencia con los puntos anteriores ${ }^{41}$.

El punto primero reconoce la existencia de coloquíntidas, una macho y otra hembra. Caracterizan a la primera, según Vélez siguiendo a Mesue, la lanígine y la dureza de la corteza, así como el color negro y el amargo del sabor de su pulpa. La coloquíntida hembra, la buena, por contra, es de corteza gruesa y suave, de sabor áspero y color blanco en su abundante pulpa. Puede objetarse que en la madurez la coloquíntida provoca graves trastornos a quien la ingiere, pues produce cólicos y evacuaciones sanguinolentas hasta acarrear incluso la muerte. Objeción que Vélez resuelve atribuyendo tales efectos a la coloquíntida mala; pero no pueden predicarse de la buena.

Para determinar si estamos ante la coloquíntida buena, hemos de fijarnos en ciertas señales. La primera es su grosor o corpulencia destacada. Pero, sobre todo, consistencia: es más ligera. Gracias a esta nota, la virtud terapéutica que encierra está más difusa, menos concentrada diríamos. Por contra, las cosas que no se hallan distendidas, sino «nudadas», son más pesadas y, por ende, de virtud concentrada. En la fisiología galenista, en efecto, los fármacos concentrados son más drásticos que los

della sola, sino de la preparada con quantidad igual de goma Arabiga, alquitira y almidó, o con igual de qualquiera destas cosas, y que si la huvieren de poner en las hieras, y en otras qualesquier medicinas grandes (que quiere dezir compuestas con muchas simples) no se ha de preparar con alguna, sino con las que entran en ellas tan solamente.» (Pharmacopoea, p.195v-196r.)

41 «Para mayor / explication me aparecio dividir este dis- / curso en seis puntos. el primero será es- / crivir la elecion de la Colocyn para que dis-/ curriendo por sus senyales, ellas mismas nos / den ha entender si es tan dañosa o, per- / niciosa como la hazen, y de qual se ha / de entender, quando los auctores dizen que / lo es. El segundo sera si se prepara por / razon del arte con la triutaration sutil. / El tercero si se prepara en las Compositiones / en que entra por razon dela sociedad. El / quarto si convenga mais prepada para / las grandes, y rebeldes enfermedades. El / quinto si es tan malitioso el modo de pur- / gar suio como de otros medicamentos amar- / gos. El sexto, y ultimo como se han de en- / tender aquellas palabras que Mes. dixo, tra- / tando delos dichos trochiscos. (Manuscrito 1v-2r.) 
livianos $^{42}$. La coloquíntida liviana es la que se cría en compañía con otras. Dentro de las que nacen juntas hay que escoger la mayor. Por lo que respecta a otra cualidad distintiva de la eficacia de un fármaco, el color, en el caso de la coloquíntida, las blancas son más allegadas al «temperamento frío» y menos drásticas ${ }^{43}$. En la fisiología del galenismo arabizado, lo áspero, seco y negro son características que definen a un fármaco de acción fuerte, en tanto que lo blando, húmedo y blanco propician una curación sin graves agresiones. Vélez refiere a la coloquíntida mala la tríada primera y a la buena, la segunda.

Siguiendo a Mesue, distingue diversos grados en la agresividad de los purgantes de acuerdo con la sustancia. Los más drásticos son los más agudos (representados por el «Euphorbium» y el «Metherion»), seguidos de los que poseen una composición de agudeza y amargor (representados por el «Scammonium») y, por fin, los de sólo amargor (representados por la coloquíntida). Siendo nada más que amarga, la coloquíntida no puede desecharse como absolutamente dañina ${ }^{44}$.

42 «de lo qual se sigue que la Co-/ locintida grande sera mejor que la pe-/ queña en quanto esta senyal, por tener / la virtud mas difusa y separada. la se-/ gunda señal de su election es que sea li-/ viana, y esta a mi parecer esta respon-/ dida, con lo que havemos dicho de la pri-/ mera: nam levitas est parvae virtutis et ali-/ menti judicium-- y que las cosas sólidas, y/ nudadas sean mas pesadas, no avra quien / lo nege, y vesse de Galeno en el lib.1./ delos Antidotos.» (Manuscrito 3r-3v.)

43 «de donde/ se ve, que la nutrition es causa dela / solidation, y la solidacion dela grave-/ dad, o, peso, con lo qual esta respondi-/ do a la razon porque conviene que la / colocintida sea liviana, pues de serlo, / se collige que no está mui mentenida, / ni fuerte para sus actiones, y por esta / propia razon quieren que no se esco-/ ja la que nasse sola en una planta,/ ni la que es de planta que nacio sola en / una region sino acompañadas con otras / plantas de su genero, y que produxo otras / muchas colocintidas, y de estas la / maior, como queda dicho. tanbien / ponen por senyal de su bondad el ser blan-/ cha, y este no es pequeño indicio, pa-/ ra que lo sea, porque quando debaxo de / un genero, ansi en plantas, como en / animales ay espetias blancas, y negras, / las blanchas son mas alegadas al tem-/ peramento mas frio, y de menores fuer-/ câs.» (Manuscrito 3v-4r.)

44 «Y por esta ra-/ son elige Mesue la Colocintida blan-/ cha, porque la de este Color es menos ca-/ liente, y eficas. tanbien dixo en su / election: Sit lenis, y este nombre sig-/ nifica la mensedumbre y blandura, y / correspondesse entrambos, porque a la per-/ çona mansa de Condicion, y passifica / la llamamos blanda, y aspera, y dura / a la que la tiene mala y es incorregible / e intratable. El significar la buena con-/ dicion muestralo Terencio in Hecyra / disiendo: Ego sum animo lenis natus non / possum adversari meis, y por occasion / dixo Mes. tratando delas Condiciones que / deven tener las medicinas de parte de / substantia. Sed, et asperi, et leni sunt / quaedam Iudicia, et enim quod hoc siccius / illud vero humidius. Lenitas nempe medi-/ cinis associata, et propria violentarum vir-/ tutum ad latus incoluminum declinare facit, / sed et alliud similiter, quanto utroque modo / sunt possibilia nasci. asperitas vero facit / e $3^{\mathrm{a}}$ nam Colocynthida lenis bona / aspera mala, etc-- de manera que de / ser lena la Colocintida le proviene / el ser mas humida que aspera, y de / ser mas humida mas segura no tra-/ to Mes del sabór dela Colocintida, / y por ser el mejor Juez, sera bien que / digamos algo de el, para que nos en-/ senye hasta donde llegan las malas, o / buenas calidades, que por su occasion / tiene, y hasta donde llega su malicia / el sabor dela colocintida es amargo, / y ella los manifiesta mui bien a lo que / la gustan, y todos los que de ella escriven / lo disen. Y de aqui consta que ay / otros dos generos de medicamentos pur-/ gantes más perniciosos, y dañosos que ella / que son propiamente los de sabor agudo / y los Compuestos del agudo, y amargo. / 
Vayamos con el segundo punto. La coloquíntida buena lo es hasta tal extremo que puede prescribirse sola, «sin la preparación de la sociedad», Basta reducirla a polvillo. A ese proceso se le llama en el arte trituración sutil ${ }^{45}$. La coloquíntida, así molida, evita la ulceración del estómago y los pliegues del intestino. Y que así deba procederse, lo funda en la autoridad de Aecio, Paulo de Egina, Serapión hijo, Avicena y Mesue.

El tercer punto, sobre «si prepara la Colocynthida en las composiciones por razón de la sociedad», tiene una respuesta afirmativa. Aduce una triple forma de acudir a la sociedad: simple combinado con simple que se oponen con su virtud a los venenos, simple combinado con simple de temperamentos contrarios y simple combinado con simple que producen efectos contrarios. Las sustancias de temperamento antagónico, cuando entran en combinación, se corrigen mutuamente, y producen un medicamento equilibrado en sus efectos. En el caso de la coloquíntida, siendo amarga, necesita la correción de una sustancia dulce: miel, azúcar u otro edulcorante. Así obraron los griegos y más tarde los árabes. No precisa de ninguna otra asociación para rectificarla ${ }^{46}$.

Va directamente contra el corazón de la argumentación de Novella y quienes le siguen el punto cuarto. Es decir, no conviene la acción de la coloquíntida preparada en todas composiciones ni debe emplearse para todas las enfermedades. El esquema argumentativo de Vélez se desarrolla aquí en una suerte de sorites propio de la farmacología deductiva del galenismo arabizado. Se parte de la opinión autorizada (Mesue, Galeno o Hipócrates). El remedio debe ser proporcional a la enfermedad. A grandes males, drásticos remedios. Pero el remedio que es insuficiente, por desnaturalizado, produce más daño que bien; en este caso, fiebres pútridas. La insuficiencia

Que sea esto verdad veese de Mes. el / cual tras, tando delos favores en sus Ca-/ nones dise: Et debes scire quod medi-/ cinarum deteriores sunt in quibus est acui-/ tas pura, scicut est euphorbium, et Me-/ therion minus autem in quibus est amari-/ tudo pura scicut est Colocintida, et / Cucumer assininus, et Similia. et quae / Composita sunt ex acumine, et amari-/ tudine sunt inter eas scicut est Scam-/ monium-Siguen este parecer todos los / autores: luego tampoco por el sabor lo / podemos jusgar por tan dañosa Como / la hasen, los que falsamente la infaman, / y clar esta, que si fuera tan venenosa que / no se atrevieran los autores a darla / sin mescla de otra Cosa, Como lo dava / Serapion.» (Manuscrito 5v-7r.)

$45 \ll \mathrm{El} \mathrm{2.}{ }^{\circ} /$ punto es si se prepara con la tri-/ turation sutil, al qual le responde / que si, y que por esta occasion la davan / sin la preparation dela Sosciedad sien-/ do buena. Que sea esto verdad, y que / se pueda dar sin la preparacion dela Sos-/ ciedad veese delas ultimas palabras / que referimos de autoridad de Serapion.» (Manuscrito, 9v-10r.)

46 «La razon / porque lo dulce la corrige es la Contra-/ riedad, que entre lo dulçe, y amargo ay, / y a esta causa tratando este sabor / Mesue en sus Canones dise: Dulce au-/ tem cum sua mediocre substantia est repres-/ sivum acuti, et amari, en otro Canon / dise: Res autem dulcis medicinas / delectabiles esse facit (et postea) et acui-/ tatem et serositatem frangit: y en otro / Res quidem dulcis omnibus medicinis / praeterquam salsae iuvamentum prestat, / De donde se vee, que con sola la mes-/ cla de las cosas dulces se corrige la Colo-/ chynthida a cuya causa la dan moli-/ da sutilmente en aguamiel comunmente / los griegos como se vera en los lugares / que quedan citados de Paulo, Aetio, y / Actuario; y esto hisieron otros grie-/ gos mas antiguos que ellos.» (Manuscrito, 12v-13r.) 
de un medicamento puede residir en su propia naturaleza o en la cantidad aplicada. Además, cuando se prepara con otros simples, pierde eficacia al verse contrarrestada por las fuerzas (principios activos, si no fuera violentar el texto) de los otros componentes ${ }^{47}$. Conscientes de esas limitaciones, sólo pondrá coloquíntida preparada allí donde lo ordenen los autores griegos y árabes. Preparación que no será general, sino específica de ella.

Ataca también a los oponentes del uso de la coloquíntida pura en el quinto punto. Contra el criterio de éstos, no es dañina. La razón que aduce se apoya en el mecanismo de acción de la coloquíntida: por su vehemente amargor, opera con tal rapidez, que purga sin causar las lesiones aducidas. Afirmación que corrobora con la autoridad de Galeno y Avicena.

Establecido, pues, que existe una coloquíntida buena, que debe molerse en polvillo y contrarrestarse su amargor con aguamiel, negado al propio tiempo que tenga que desvirtuarse su eficacia con la asociación de otros simples y que dañe, está ya capacitado para resolver el pleito, que no es otra cosa que interpretar adecuadamente el texto de Mesue a propósito de la confección de la hiera de Hermes. Y ese el tema del punto sexto. Procede iniciando un análisis terminológico. La frase Confectio trochiscorum Alandahal qui ponuntur in hyera Hermetis et in aliis confectionibus loco colocinthydae es una anfibología, vicio que en la lógica aristotélico-escolástica es característico del razonamiento sofista. Anfibología que no cometió Mesue, sino quien lo tradujo del árabe al latín. La interpretación verosímil que él acepta es que, por la expresión in aliis, debe entenderse sensu stricto otras confecciones de Hermes; sensu lato (o modo largo), ciertas confecciones de Mesue y de otros autores. De ninguna forma puede aceptarse que se refiera a todas las confecciones. Para corroborar su tesis, contextualiza esa expresión de Mesue con otras suyas en que habla del empleo de trociscos de alhandal en vez de coloquíntida. De esa contextualización se infiere que, cuando se deben poner trociscos, se indica expresamente, y así también cuando quieren que se ponga coloquíntida ${ }^{48}$. Corrobora la interpretación que ha dado del texto de Mesue con las enseñanzas de Galeno, en particular, con el principio de que las medicinas deben usarse en proporción a las enfermedades. Para terminar con una recapitulación sobre cómo proceder en el uso práctico de la coloquíntida. Primero, anota, atenderemos a su prescripción: eliminar la flema y humores viscosos, ex-

\footnotetext{
47 «de donde se colige los / daños tan grandes, y manifestos, que / hara la Colocynthida si se pone en / los medicamentos en que no se pide pre-/ parada, corregida, y quebrantadas / sus fuerças con la mezcla del Bdellio / y tragacantho: pues por esta rason, no / solamente se les desminuiran, o menos / cavaran sus fuerças, pero por llevar / menos la mitat de lo que avian de lle-/ var dela Colocynthida que lo que pidieron / sus autores.» (Manuscrito, 14v-15r.)

48 «pues vemos que estos / echaron estos trochiscos en estas dichas / Confectiones, pero no en todas en gene-/ ral, sino es en aquellas que los piden. Que / no se ayan de poner generalmente en / todas, veesse con evidencia, porque adonde / el, y los demás quisieron trochiscos los / pidieron, y adonde Colocinthyda tambien» (Manuscrito, $18 \mathrm{v}$.)
} 
trayéndolos de los recovecos del cuerpo. Luego, evitaremos se devalúe con otros simples que menoscaben su eficacia, en tanto que buscaremos los que ayudan a su acción. Quiebran su eficacia y no ayudan los trociscos. Por tanto, la razón está de parte del Colegio de Médicos de Zaragoza y debe reprenderse a Cosme Novella.

\section{APENDICE: TEXTO DEL MANUSCRITO}

(1r)

\section{IESUS MARIA -}

Informacion hecha por Francisco Vélez de Ur ciniega, boticario del Ilto. de Toledo a petition del Collegio de los Medicos y Cirujanos de la Ciudad de Zaragoça, para el pleyto que trata contra Cosme Novella acerca del uso que se deve tener de la Colocinthida.

Tratasse, y esta puesto en controversia si se han de poner los trochiscos de Alhandal en todas las Compositiones en que se pide Colochintida, ó en solas aquellas en que los auctores los piden determinadamente por su propio nombre, ó en que piden Colochyntida preparada. La occasion de esta difficuldad han sido aquellas palabras que Mes. escrivió en su antidotario, tratando destos dichos trochiscos, que son las siguientes. Confectio trochisconum Alhandal, qui ponuntur in hyera Hermetis, et in aliis Confec. loce Colocynthidae. Y como los paraceres de los hombres sean

(1v) tan differentes, que han dado occasion a que se hissiese aquel adagio tan antiguo quot Capita tot Sententiae- de aquí tanbien ha resultado, que unos la entendian de una manera, y otros de otra; Aunque la explication de ellas se podía tratar con mucha brevedad, por no ser mas que declarar que signifique acerca de los que en- tendien la lengua latina in aliis. Y si diziendo Mes. in aliis quiso dezir in omnibus como lo entendien los que no la enteadien: sera necessario de tomar la corrida de mas atras, para ensenyar a saltar a los que tropezando en ellas caen en este barrancho deslumbrados con algunas auctoridades de algunos auctores que entendieron mal lo que dixieron los Arabes antiguos, o por no entenderlos los que los leen por falta dela inteligencia dela latinidad. Para maior explication me aparecio dividir este discurso en seis puntos. el primero sera escrivir la elecion de la Colocyn. para que discurriendo por sus senyales, ellas mismas nos

den ha entender si es tan dañosa o, perniciosa como la hazen, y de qual se ha de entender, quando los auctores dizen que lo es. El segundo sera si se prepara por razon del arte con la triutaration sutil. El tercero si se prepara en las Compositiones en que entra por razon dela sociedad. El quarto si convenga mais prepada para las grandes, y rebeldes enfermedades. El quinto si es tan malitioso el modo de purgar suio como de otros medicamentos amargos. El sexto, y ultimo como se han de entender aquellas palabras que Mes. dixo, tratando delos dichos trochiscos. La elecion de la Colocynthida que para tratar del punto que primero conviene, es la siguiente. Elec- 


\section{JOSÉ MARÍA VALDERAS}

tio duorum est modorum masculos sc. et foemi. et eius est masculus supra quem nascit sicut lanugo, et etiam gravis in duritie, et asperitate attinens nigredini: Et laudat ex eis foemina et proprie habens proprietates has bonas: ut sit Colocynthida grossa, et levis et quanto levior, melior: et sit laxa, et alba, et lenis

(2v) et completae maturitatis et cuique pars interiori populosa et laxa, et levis et alba vehementis albedinis. Verumque non est completa in maturitate mala? Conturbat. enim suscipientem eam, et ventositatem cum difficultate facit, et solvet superabundanter: et solutione educit sanguine, et fortasse interficit. Et cum sigillatur ex toto germine plantae ut nascatur Colocynchida una, est illa mala et perniciosa, imo est venenosum. Et cum in tota regione non est nisi planta eius una posse nascens est mala: et quae nascitur in terris fortibus et pulverulentis, aut juxta loca reptilium, aut locus termarum Colocynthidas facit minores et sunt similiter malae, quae enim nascunt in terris laxis et arenosis, et liberis est quae eligitur. Etc. Todos los danyos que dizen que ahze la Colocynthuida (como se ha visto de la que havemos referido de autoridad de Mes.) atribuien los autores a la que es mala, porque la que es buena no los puede ahzer, y la razon de esto se

(3r) cehera de ver, considerando con atention y cuidado sus señales. Entre las demas que Mes. enseña es la primera que sea gruessa o, corpulenta, y esto mismo encomendó en los Canones, donde dando la razon porque conviene que lo sea dizen: Et scire debes quod magnitudo rei, et parvitas virtutis diffusionem et aggregationem facit, et ideo Colocynthida magna melior. Etc. Quod mihi non consonum esse videtur praecipue in unius speciei rebusque: siquidem parvitas aggregationem virtutis, magnitudo vero diffusionem demons- trat. Unita virtus fortiori se ipsa dispersa. Aristo. cap. 1. Lib.4 Meteo. Gal.cap. 11. lib. I Simpl. et Aprhodiseo Proble. 21 Sect. 1-- de lo qual se sigue que la Colocintida grande sera mejor que la pequeña en quanto este senyal, por tener la virtud mas difusa y separada. la segunda señal de su election es que sea liviana, y esta a mi parecer esta respondida, con lo que havemos dicho de la primera: nam levitas est parvae virtutis et alimenti judicium-- y que las cosas sólidas, y

nudadas sean mas pesadas, no avra quien lo nege, y vesse de Galeno en el lib.1. delos Antidotos, donde tratando dela election delas razones, dize: Ignobilia autem habent, quae in suo genere, et tenuiora, et exiliora: prestant enim in quolibet genere nec rugosa, nec exilia; quemadmodum, quae modum excedunt, deteriora judicantur, his quae bene, nutritam, solidamque habent concistentiam etc.- de donde se ve, que la nutrition es causa dela solidation, y la solidacion dela gravedad, o, peso, con lo qual esta respondido a la razon porque conviene que la colocintida sea liviana, pues de serlo, se collige que no está mui mentenida, ni fuerte para sus actiones, y por esta propia razon quieren que no se escoja la que nasse sola en una planta, ni la que es de planta que nacio sola en una region sino acompañadas con otras plantas de su genero, y que produxo otras muchas colocintidas, y de estas la

maior, como queda dicho. tanbien ponen por senyal de su bondad el ser blancha, y este no es pequeño indicio, para que lo sea, porque quando debaxo de un genero, ansi en plantas, como en animales ay espetias blancas, y negras, las blanchas son mas alegadas al tem- 
FRANCISCO VÉLEZ DE ARCINIEGA EN LA POLÉMICA DE LA COLOQUÍNTIDA

peramento mas frio, y de menores fuercâs. Nam unumquodque in suo genere nigrum, calidius est quam album. que sea esto verdad, vesse de Isaac en lib. 2. de su practica, que tratando de medicinis $4^{\circ}$ gradu repositis dize: piper nigrum calidius est, et siccius albo, et propter hoc antiqui dederunt piper album ad confortandum, et parum calafaciendum, et nigrum insidendum, et urendum, nimisque calafaciendum. Podrasse aqui poner difficuldad acerca de si esta proposicion de Isaac sea verdadera por desir Gal. tratando dela pimienta blanca lib. de Sim. med. facul. 8. Porrò frutex qui velut omphax est piper album est, nigro quidem aerius.- y como la acrimonia procede del calor parece que ha

(4v) de ser mas caliente la blancha que la negra contra el parecer de Isaac. Pero desta duda nos saca el propio Galeno con las palabras que consecutivamente escrivio diziendo: nam illud iam quasi superassatum, et exicatum est. de manera que la razó de ser menos caliente, y aguda la pimienta de que aqui hiso mention el dicho Gal. es por averse assado y resecado con el gran calor del sol, a causa de averse dexado mas tiempo del que era necessario en las plantas que la producen, porque a todos los medicamentos agudos les sucede esto, como se vee de Mes. en el tratado de la assación en sus Canones y de Gal. in proemio lib. 9 Simp.med. pues por la assación se hasen mas mites. de donde consta que si se cogiera en devido tiempo, fuera mas caliente, y aguda la negra que la blancha. Que sea esto ansi veese de Diosc. que tratando de las pimientas en el Cap. 153 del lib. 2 dise -- Piper nigrum vero, utpote quod tempestive

(5r) maturitate collectum sit, odoratum etiam conant candido suavis, et acris- Luego si la acri- monia y el olor provienen del calor, y es más olorosa, y aguda la negra que la blancha si esta cogida en su perfeccion sera mas caliente? Para maior inteligencia será bien referir aqui algunas autoridades, que confirman lo dicho en general, y sera la primera del Cap. 27 del lib. 3 de Causis plantarum de Theophrasto donde dize: Infirmiora, fragilioraque sunt omnia (ut simpliciter loquar) alba quam nigra, tam in plantis, quam in aliud genere- Confirma tanbien esta opinion Haly en el Cap. 7 del lib. 2 de su practica intitulado de probatione medicaminum et colorem donde dize: Signatio autem de colore medicaminis complexionem demonstrans sube odori: Signa enim quae ab eo sumuntur debilia sunt: inveniuntur namque in uno quoque colore complexiones calidae, frigidae, siccae, et humidae quum tamen signatur habitudo cujusdam

rei ab alia, ut signantur plurima seminum, et sepi, et succi et colores eorum: quemadmodum Caepe immunia cepa Ansali: et quoniam quecumque earum alba sunt minoris sunt caloris; quae vero rubicundiores majoris Caloris. Sic quoque se habet res in Cicere, faseolis et Lauresis: quaecumque enim horum alba sunt frigidioris sunt Complectionis, quae autem rubicundiora, et nigra minus frigida, et magis, ad calorem inclinantia etc-- Y por esta rason elige Mesue la Colocintida blancha, porque la de este Color es menos caliente, y eficas. tanbien dixo en su election: Sit lenis, y este nombre significa la mensedumbre y blandura, y correspondesse entrambos, porque a la perçona mansa de Condicion, y passifica la llamamos blanda, y aspera, y dura a la que la tiene mala y es incorregible e intratable. El significar la buena condicion muestralo Terencio in Hecyra 
JOSÉ MARÍA VALDERAS

(6r) disiendo: Ego sum animo lenis natus non possum adversari meis, y por occasion dixo Mes. tratando delas Condiciones que deven tener las medicinas de parte de substantia. Sed, et asperi, et leni sunt quaedam Iudicia, et enim quod hoc siccius illud vero humidius. Lenitas nempe medicinis associata, et propria violentarum virtutum ad latus incoluminum declinare facit, sed et alliud similiter, quanto utroque modo sunt possibilia nasci. asperitas vero facit e $3^{\mathrm{a}}$ nam Colocynthida lenis bona aspera mala, etc- de manera que de ser lena la Colocintida le proviene el ser mas humida que aspera, y de ser mas humida mas segura no trato Mes. del sabór dela Colocintida, y por ser el mejor Juez, sera bien que digamos algo de el, para que nos ensenye hasta donde llegan las malas, o buenas calidades, que por su occasion tiene, y hasta donde llega su malicia el sabor dela colocintida es amargo,

(6v) y ella lo manifiesta mui bien a los que la gustan, y todos los que de ella escriven lo disen. $\mathrm{Y}$ de aqui consta que ay otros dos generos de medicamentos purgantes más perniciosos, y dañosos que ella que son propiamente los de sabor agudo y los Compuestos del agudo, y amargo. Que sea esto verdad veese de Mes. el cual tratando delos favores en sus $\mathrm{Ca}$ nones dise: Et debes scire, quod medicinarum deteriores sunt in quibus est acuitas pura, scicut est euphorbium, et Metherion minus autem in quibus est amaritudo pura scicut est Colocintida, et Cucumer assininus, et Similia. et quae Composita sunt ex acumine, et amaritudine sunt inter eas scicut est Scammonium- Siguen este parecer todos los autores: luego tampoco por el sabor lo podemos jusgar por tan dañosa Como la hasen, los que falsamente la infaman, y clare esta, que si fuera tan venenosa que

no se atrevieran los autores a darla sin mescla de otra Cosa, Como lo dava Serapion, como se vee del Cap. 282 donde tratado dela buena, y mala de autoridad de Abixer, dise:

Colocynthida est melo agrestis quae quando sumitur in potu purgat phlegma grossum, quod advenit iunctus, et illud phlegma, quod emittit fumositates ad caput, et expellit humores qui agregantur in corpore ex melancholia, et aliis malis humoribus. et oportet quod quid colligit Colocin. Colligat eas in fine sui anni, quando sunt maturae, et color earum incipit fueri citrinus, et non colligat illa quae est viridis, quando videlicet incipit condensari sua rosa; aut dum ipsa habet aliquid viriditatis quoniam modicum ex ipsa occidit, et praecipue quae reperitur sola in arbore sua occidit potantem sine dubio: quoniam quando datur ex pulpa sua facit torciones fortas, et evomere fortiter, et laxatio sua sine

juramento, et inducit renes monem, et anxietatem animae et Cohortationem anhelitus, et frequentiam eius, et Sincopim, et Sudorem frigidum, et fortassis interficit, scicut dixi. Sed quando colligitur postquam citrinatur pomum eius, et est perfecte maturum, et hoc est quando advenit frigus ei videlicet quando acceditur lampas sc. in mense septembris in principio auctumni confert potanti et expellit humores, quos volumus purgare, et non est necesse quod misceatur cum medicina alia etc- de donde se vee que todos los daños que disen que hase la Colocintida los atribuien los auctores ala mala, y no ala buena, pues la buena se pueda dar sola sin mescla de otros medicamentos, como la davan no 
FRANCISCO VÉLEZ DE ARCINIEGA EN LA POLÉMICA DE LA COLOQUÍNTIDA

solamente Serapion, y muchos delos Arabes, mas también los Griegos Como se vera en los lugares que despues se citran de Paulo Aetio, y Actuario. Y el no ser venenoso la Colocinthida

\section{(8r) buena, con}

Serapion,

de supr

diversita

atribuien

y no a la bu

y en el Canon

malignam di-

se que ay dos que

son maliciosas, las desen-

frenadamente, y que mela-

tiosas a toto genere del numero de los quales son el methereon, tartago, et euphorbio, y otros que son maliciosos accidentalmente assi como el turbith negro y el agarico negro, y duro, y la colocintida que nasce sola en su planta, y la escamonea corascena. da entender lo mismo del Canon, que comiença Caeterum quaecumque, donde dise Sunt scamonea et aloe leviores quidem meliores, et Colocintida similiter. tambien lo muestra

(8v) disiendo: Sin-

bulam facit

endo a ensen-

mejor. $\mathrm{y}$

nt autem san-

dise: et de

aloe malus

quem ter Cucumera

Assinios, et Colochynti.

quae planta sua. etc.

que no sea la Colocintida malitiosa a toto genere sino ex accidente veesse de Tagaeccio que en la explication del Canon referido que comiença: Nam sunt et malignarum etc. dise: medicina vero maleficae essent malignae effrenesque insalubres appellantur. Porro malefica eiusmodi medicina purgantia simplicia (de his solum hic est sermo) duplicia sunt. toto genere, seu tota specie malefica. ex accidentia solum, et secundum aliquod indicium sui generis maligna. Toto genere malefica

dicuntur quando totum genus malignum est, et insalubre cuiusmodi sunt methereon glebre, id est grana Lathyris quam Cataputiam minorem vocant, Euphorbium gummi urentis facultatis, Sagapenum quod corrupte Serapinum vocant. Medicinae sunt toto quidem genere maligna, sed secundum aliquod indicium, quod ad propria sui generis degenerant natura, sunt veluti agaricum nigrum, turbit nig. scammonium Indicum, vel Libium Colocinthys unica seu singularis in planta sua, vel in unica regione unica planta. Confirmalo lo mismo Sylvius en la exposition de este dicho Canon disiendo: qua-propter tua interest medicamenta malefica a salubribus discernere. Sunt autem malefica quaedam toto Genere quorum virtus effrenis omnibus est cognita, velut thimeleae, Lathyris, euphorbium alia (specie tantum vel accidente maligna, eaque) in multis generibus

ut turbith nigrum, et agaricus niger, sua Scammonium suniticum, etc. de todo lo qual se vee con evidencia que jusgan ciegamente los que atribuien los danyos que aze la Colocynthyda mala ala buena, y que no la saben discernir. y esta causa dise mui bien Syl. y antes que el Mesue. quare tua interest medicamenta malefica a salubribus discernere Entendiendo por malefica (como queda dicho) a la Coloquintida mala, y por la saludable 
JOSÉ MARÍA VALDERAS

ala buena, pues la que es buena es tan buena que se pueda dar sin la preparacion dela sosciedad siendo molida sutilmente, que es el segundo punto que dixe se avia de tratar. El 2. punto es si se prepara con la trituration sutil, al qual le responde que si, y que por esta occasion la davan

(10r) sin la preparation dela Sosciedad siendo buena. Que sea esto verdad, y que se pueda dar sin la preparacion dela Sosciedad veese delas ultimas palabras que referimos de autoridad de Serapion que son. Et non est necesse quod misceatur cum medicina alia: quando dise mas abaxo: Si igitur volueris Colochyntidam rectificare, aprueva, y no contradise alo dicho; que no necessita el averse de corregir, pues que dise: $\mathrm{Si}$ quisieres dexandolo a la volundad del que la ha de dar. Confirma lo mismo Nicolao Mutono en la explication de esto dicho lugar de Serapion, disiendo: lecta vero cum ceperit in pallidiorem colorem mutari exacteque matura, frigore nimirum accedente, aequinocti autumnali mense quidem septembris initio autumni, assumentibus auxiliatur, humoresque noxios pellit, nec opus est, ut aliis medicamentis emendetur.

(10v) Y que no tenga necessidad de emienda, corroborasse con lo que diremos en el quinto punto de autoridad de Galeno y Avicenna : y en quanto a la trituration sutil digo, que se prepara con ella por razon del arte. que sea esto verdad veesse de Mesue pues aviendo dicho primero en sus Canones: Inquit haben Mesue non tam has fugire oportet verum, et omnes etsi elegantiores sunt: nisi observentur conditiones, et modi quorum rememorabimur si deus voluerit. Por ser las condiciones, y modos sus preparaciones, tratando de la trituration dise despues: Exemplum tertii inquit filius Serapionis oportet ut Colocinthyda et propria interius ultime pulverisetur, nec sit contentus aliquis in sufficientia triturationis eius: pars enim sensata ex ea adhaeret in viliis stomachi et involutionibus intestinorum, et ex ea quam invenit humiditate invibita inflatur

et apostemas aut ulcereat loca. trita vero ultima trituratione non operatur illud. de donde se ve con evidencia que se prepara con sutil trituracion. Son de la misma opinion de Mesue, Aetio, cap. 39. Serm. et lib. 1. paulo Cap. 4. lib.7 de octovario in Antidotis Avicennae lib. et tract. 2. Cap. 22 y el hijo de Serapion de quien el lo tomo en el Cap. 12 del tratado de los Antidotos. El punto terçero es, si se prepara la Colochyntida en las compositiones por rason dela Sosciedad. A lo qual se responde que sí, y que con ellos se preparan los medicamentos de dos maneras (como de autoridad de Damocrates lo dise Mes.) La una es si con los medicamentos que propriamente se oponen con su virtud $3{ }^{a}$ el veneno y calidad enemiga de nuestra vida, o naturaleza: La otra con la mescla de aquellas cosas que tienen contrario temperamento mudandoles

su fria, caliente, humeda, o seca destemplança: La terçera con la mescla de las cosas que haze los effetos contrarios. estas maneras de preparacion escrivió gallardamente fallopio en el Cap. 27 del tratado de medicam. purg. sim. donde se podra leer mas cumplidamente en el qual dise: Corrigimus quoque in pharmacis qualitatem manifestam, ut quando est nimis calidum admiscemus fri- 
FRANCISCO VÉLEZ DE ARCINIEGA EN LA POLÉMICA DE LA COLOQUÍNTIDA

gida, ut exhibituri sumus euphorbium vel staphidem agriam cum sint acria, et pretermodum calida corrigimus eorum nimiam caliditatem admiscentes refrigantia. Si vero pharmacum sit nimis siccans admiscenda sunt humectantia, et hoc fuit inventum non arabum, ut quibusdam videtur sed graecorum, et praecipue Rufi qui fuit graecus author, et quidam antiquus ipse sane ut videre est apud oribasium in 7. ${ }^{\circ}$ Collectaneorum Cap. 27 fuit qui dixit, quod pharmaca pretermodum cali-

da sunt retundendaque ad mixtionem refrigerantium: id etiam dico, et aliis qualitatibus manifestisque tertiaria enim sunt castigandae ut voluit ruffus. Hoc autem verum est quod praeceptum hoc est optime observandum ab Arabibus, ut videre potestis in suis compositionibus in quibus nihil relinquare, quod non sit castigandum: unde compositiones Arabum sunt ita pulchre mea sententia ut pulchriores non sit invenire. Ille Graecorum sunt certe pulchre sed superantur $\mathrm{ab}$ aliis Arabum ut etiam experientia docet, quia quotidie exhibimus electuaria et alias Compositiones arabum, sine noxa, et nullam ex usu ipsarum vidimus fieri super purgationem, etc.- $\mathrm{Y}$ si como es verdad, y dise este auctor no dexaron en sus compositiones los arabes cosa alguna que poder corregir, y no se que es lo que quiere emendar el que se ponga en las Compositiones en que no se pide preparada la Colocinthida. Que se corrigan

(12v) los medicamentos simples con la Sosciedad vese de Galeno in Com. 11 et 12. Comentarii 3 in lib. devat. vict. in morb. acut. et cap. 9 lib. 1de Comp.med. purg. et lib. quos quibus etc.de Cesalpino. cap. 4. et 19 lib. 2 de med. facult. y acerca de esto se allaran otros muchos lugares citados de diversos autores y en el fin de mi
Pharmacopeia y por aver tantos, fuera de los citados que lo digan solamente dire agora cómo se prepara con sola la mescla de la miel, o açucar, u otra cosa dulce la Colochyntida. La razon porque lo dulce la corrige es la Contrariedad, que entre lo dulçe, y amargo ay, y a esta causa tratando este sabor Mesue en sus Canones dise: Dulce autem cum sua mediocre substantia est repressivum acuti, et amari, en otro Canon dise: Res autem dulcis medicinas delectabiles esse facit (et postea) et acuitatem et serositatem frangit: $y$ en otro

Res quidem dulcis omnibus medicinis praeterquam salsae iuvamentum prestat, De donde se vee, que con sola la mescla de las cosas dulces se corrige la Colochynthida a cuya causa la dan molida sutilmente en aguamiel comunmente los griegos como se vera en los lugares que quedan citados de Paulo, Aetio, y Actuario; y esto hisieron otros griegos mas antiguos que ellos. El 4. ${ }^{\circ}$ punto es si convenga la accion dela preparada en todas las Compositiones y para todas las enfermedades, al qual se responde que no, porque para grandes, y rebeldes enfermedades son necessarios grandes, y fuertes remedios. Extremis morbis, extrema diligentissime remedia sunt adhibenda (ut aucthor est Hyppocrates aphoris. 9. lib. 1.) Praecipites enim sunt, et acerrimi, ut appoplexia qui quae brevi oppressuri sint vires,

et extincturi. In quibus etiam morbis materia turget suoque motu, et instabilitate omnia conturbat, statim initio valentissimum medicamentum dandum est. Praestat mea quidem sententia a nonnullo virium dispendio morbum discutere, quam sinere, ut ea materia aliquam prin- 
JOSÉ MARÍA VALDERAS

cipem partem obruat, et nullo subsidio universae vires mox collabantur, ut concidant. Causae morborum magnae inveteratae expulsu difficili, valentiora medicamenta sunt necessaria. Esto confirman Galeno, Paulo; y no lo ignoró esto Mesue, pues hablando dela Colocynthida mala, y delos otros medicamentos maliciosos ia referidos, dise: A quibus elongari oportet nisi forsitan congruat, nam in quibusdam morbus competit venenum etc. Y cosa llana es que un pequeño, flaco, y sin fuerças, no podra rendir a su contrario

(14r) si es fuerte, grande, y poderoso, y de no purgar el humor que se dessea, $y$ conviene, sucederia al enfermo grandissimo daño. Entre los demas canones que Mes. escrivio en el cap. 1. del Theorema 3 al principio dise: Intentionis tertiae si medicina movet, et non purgat cap.1. Auferamus igitur hic sermones exponentes unamquamque harum divissionum et primo si medicina solutionem non fecerit, aut fecerit tardam- Y despues de aver tratado otras causas por cuia rason no purga la medicina, $\mathrm{y}$ dicho que es causa el no purgar para engendrarse fiebres putridas, syncope, y presta muerte dise: Aut quae medicina est debilis, et remissa in operatione sua-- y esta es la sexta, y ultima rason que dise que es la causa de estos danyos. dela qual escrvio tanbien Avicenna fen.4. cap.4. lib. 1. y es necesario advertir quel medica-

(14v) mento pueda ser debil por dos rasones, natura scilicet vel qua ipsius quantitas parva data est ad humoren vacuandum corporis natura, et aliis necessariis limitationibus. Cum hoc advenit, vel a natura superatum (ut ex Avicenna, Sera- pione, Aetio, cap. de Scammonio, et a Gal. lib.4 sanit. tuendae videre est) in alimentum convertitur, vel delateriam vim contrahit, cuius rei etiam testis est Oribasius lib. 14 Collect. cap. 41 dicens quaedam medicamenta cum purgatione frustrantur in corruptelam, et tanquam in venenum convertuntur-- de donde se colige los daños tan grandes, y manifestos, que hara la Colocynthida si se pone en los medicamentos en que no se pide preparada, corregida, y quebrantadas sus fuerças con la mezcla del Bdellio y tragacantho: pues por esta rason, no solamente se les desminuiran, o menos cavaran sus fuerças, pero por llevar

menos la mitat de lo que avian de llevar dela Colocynthida que lo que pidieron sus autores. Que maior error se podia aser, que poner en la hiera que Nicolao escrivio de autoridad de Galeno en la diacolocynthidos que escrivio Mes. de autoridad de Rufo, y en la Hyera logadion que escrivio Aecio, ó Nicolao los trochiscos de Acandal, pues todos sus autores fueron anteriores a Mesue, y a ellas las compusieron para tan rebeldes, y grandes enfermedades. Si no vasta lo dicho, vaste que lo dise Serapion en el lugar ya citado, y Nicolao Mutono su interprete: Hieris autem, magnisque medicamentis inijicienda est Colocynthis, minime cum aliis medicamentis, nisi cum illis, quae medicamentum componunt admitenda vis eius admodum in frenanda- de donde

se sigue, que no se ha de poner corregida, si no es solos en aquellos medicamentos, en quien no entra quien la corrija, y es necessaria su correcion, y en estos tales la piden los autores pre-

Asclepio-Vol. LII-1-2000 
FRANCISCO VÉLEZ DE ARCINIEGA EN LA POLÉMICA DE LA COLOQUÍNTIDA

parada, y se vee que no es mas segura la preparada en general, sino particularmente. El quinto punto es si la Colocinthyda no preparada podra haser, siendo buena, los daños que disen que hase los que con poca curiosidad, y cuidado lo han considerado, alos quales se les niega el poderlo haser, por rason del modo que tiene de purgar tan presto, que passa por las tripas sin danyarlas, ni imprimir los daños que parece pudiera, por razon de su vehemente amargor. Que sea esto verdad veesse de avicenna en el lib. y tratado 2. cap. 12, donde dise: Et propter velocitatem sui exhibitam ex intestinis, non

(16r) ultimantur impressiones eius quae expectantur ex amaritudine sua. Confirma este parecer Galeno lib. 7 de Sim. medicam. facul. disiendo: Colochyntis gustu amara est, sed quae alii amaritudinis dum potatur adsunt opera, ea evidenter efficere nequit, ob purgatoriam facultatem, quam validam in se continet: nimirum cum iis, quae expurgant, ante, et ipsaque alvum externi prevertentes, etc.El sexto, y ultimo punto punto es, la explicacion delas palabras ia referidas que dixo Mesue tratando delos trochiscos de Alhandahal que son las que se siguen: Confectio trochiscorum Alandahal qui ponuntur in hyera hermatis et in aliis confectionibus loco colocinthydae. Estas palabras son amphibologicas por ser algo dudosas. Nam $\alpha \mu \varphi \imath \beta$ o $\lambda$ o $\gamma \imath \alpha$ est dubium dictum, vel sermo dubiam sententiam indicans, fitque haec figura vitio compositionis, quia in

(16v) ambigua posita sententia est: et fit diversis modis, $\mathrm{Y}$ aqui la cometio el que traduxo a Mesue dela lengua Abraica en la Latina. Porque quando dixó: et in aliis confectionibus, no declaró si estas avian de ser de hermes (que es lo que tiene mas apariencia de verdad) o del mismo Mesue, o de otros autores en general. Pero lo que quiso desir es que estos dichos trochiscos no se pusiessen generalmente en todas las Confectiones, sino en la Hyera de hermes en lugar de Colocinthyda, y en otras Confectiones del dicho hermes. bien se podria entender aqui tomando el sentido destas palabras largo modo, que se avian de recibir también en algunas Compositiones de Mesue, y de otros autores, pero no in omnibus, porque el que dixesse que in aliis quiere desir in omnibus con mui justo titulo se le podria desir que era ignorante dela Lengua Latina passan-

do pues con esto nuestro discurso adelante, (17r) sera bien dar demonstracion, de que Mesue quiso que se pusiessen estos trochiscos en la hyera del dicho Hermes loco Colocinthydis, y en otras Confectiones del dicho Hermes, y tanbien que se puede entender en algunas suyas, y de otros autores, pero no en todas que los quisiesse poner en la hiera de Hermes en lugar dela Colocinthyda, consta del capítulo de Luf. que el propio Mesue escrivió entre los demas simples purgantes, en el qual escrivio la hiera de este autor, y en ella pidio (como el mismo Hermes lo avia pedido) Colocynthida, y no los tro. de Alandahal, pues dise en su receta Interioris colocinthidae-- escrivio despues esta propria hiera en su antidotario, y pidio en ella trochiscos de Alandahal, disiendo: Hiera Hermitis et est cum hiyera Luf.

recipit trochiscorum Alhandal audencia, que en esta dicha hiera quiso 
JOSÉ MARÍA VALDERAS

Mesue (como el los puso) que se pusiessen en lugar dela Colocinthyda, que Hermes, y en el dicho capitulo puso los trochiscos de Alandahal, y que por ser menos efficaces que ella, puso por ocho dragmas dose dellos, que son ocho aureos. Tan bien pidio trochiscos de Alhandahal en unas pildoras que escrivio en su antidotario de autoridad del dicho Hermes, de donde se collige, que quiso desir, que se pusiessen en la dicha hiera en lugar dela Colocinthida, y en otras Confectiones deste dicho autor. Si tomamos largo modo por rason dela amphibologia aquellas palabras in aliis Confectionibus, podremos entender, que se avian de poner en algunas Confectiones de Mesue, porque

(18r) en las pildoras de Alandahal, que por no aver puesto cuias son se entiende ser de su autoridad, las quales escrivio en el Antidotario, pide trochiscos de Alhandal. Podrasse tambien entender tomadas como dicho es las dichas palabras, que quiso desir tanbien en otras Confectiones de otros autores, fuera de las de Hermes, y las suyas, y puedesse provar con algunas recetas de diversos autores, que el dicho Mesue escrivio; entre las quales son unas pildoras intituladas: Confectio pilularum Ruffi conferentium ad sodam etc. En las quales pide tres drachmas de ellos en las intituladas. Confectio Pilularum Alchindi pide de ellos dros drachmas. en las pildoras que escrivio intituladas de oppopornaco en el capítulo de paralisi de autoridad de Joannicio pide de trochiscos de Alandahal seis drachmas.

(18v) de donde se podra entender tomadas largo modo las dichas palabras, que tambien quieren desir en otras Compositio- nes de otros autores, pues vemos que estos echaron estos trochiscos en estas dichas Confectiones, pero no en todas en general, sino es en aquellas que los piden. Que no se ayan de poner generalmente en todas, veesse con evidencia, porque adonde el, y los demás quisieron trochiscos los pidieron, y adonde Colocinthyda tambien. Pidio Colocynthida en las pildoras aggregativas de su invención, en las aggregativas maiores, en las Indas de Helii, en las de Sarcocolla, en las foetidas mayores, y menores, en las de euphorbio, en las de Luce majores, y menores en las de Agarico, en las de Colocynthida, en las de opoponaco, en las de hermodactiles majores, que escrivio en su antidotario, pide absolutamente Colocynthida, di-

siendo: Recipe coloquinthidae etc. En las que escrivio intituladas Pilulae nostrae conferunt aegritudini capitis, pide Coloquintida interioris, lo mismo pide en las de Oribasio, intituladas Confectio pilularum mundificativum caput; y en las de sabor behengirges, intituladas Confectio pilularum indarum, y en las de Alexandro intituladas Confectio pilularum valentium ad diuturnam sodam, y en las que escrivio de autoridad de Galeno intituladas Confectio pilularum cocciarum, dise Recipe Coloquintidae interioris albae, et lenis, todas las quales escrivio en el tratado de Soda, y esto hiso en otras Confectiones, de donde se vee, que aquellas palabras, in aliis Confectionibus, se han de entender stricto modo en la Hiera de Hermes, y en otras Confectiones deste autor, y largo modo en las suyas

de otros Autores, y que se puede provar, pero no en todas, sino in aliis idem en otras algunas. tanbien se puede provar que no 
FRANCISCO VÉLEZ DE ARCINIEGA EN LA POLÉMICA DE LA COLOQUÍNTIDA

los quiso en todas, pues ay algunas Compositiones, que piden lo uno, y lo otro. Verase esto en la hyera diacolocynthidos, que el propio Mesue escrivio en su antidotario de autoridad de Rufo, pues pide en ella de Colocynthida buena, y escogida viente drachmas, y luego dise; Et alio loco (id est codice 7) Coloquintidae trochis.Alandahal anas 3 xxv-- Dando a entender que esta hiera se conponia algunas veses con sola la Colocynthida, y otras con ella, y con los trochiscos. Todo lo dicho se puede provar con autoridad de Galeno porque el, y los demas autores doctos usan de las medicinas en las enfermedades conforme ellas mismas las piden, y a essa causa, unas veses preparan mas, y otras menos a los medicamentos expurgantes: y ansí el dicho Gal. pidio en

(20r) las pildoras, que escrivio en el cap. 14 del lib.9. de su methodo, para que fuesse mas corregida la Colocynthida y las demas cosas el Bdellio, y la goma Arabiga. En otras que escrivio en el capi. $8 \mathrm{del}$ lib. 14 dela dicha methodo, no pidio gomas, sino solamente azibar, Scammonea, y Colocynthida contentandose con que las dos cosas se corrigiessen con el azibar. Nam ut inquit Mes. suo cap. est aliarum medicinarum rectificator bonus. en otras pildoras que escrivio en estos proprios simples, senyalando dellos las cantidades en el cap. y lib. 1 de Comp. pharm. sec. toc. puso con ellos el Zumo de Axenjos, diciendo: His ego unam partem succi Absynthii addo. Antea vero etiam mastichem chiam, et bdellium adieci. hoc enim modo. Quintus utebatur verum propterquod ea reiiecerim, postea alio sermone explicabitur etc. De donde se vee

(20v) clara la variacion que tienen los autores en el usar delos compuestos, $y$ que Galeno tanbien usava dela Colo- cynthida, unas veses corregida con gomas, y otras sin ellas: y para que se eche de ver con evidencia, que no se deve poner en todas las Compositiones corregida. Pongamos por exemplo, que queremos purgar con ella, lo primero que Mesue dise, tratando de su Posse en su mismo cap. Posse (inquit) solutione educit phlegma, et humores viscosos attrahens ipsos a profunditate membrorum, etc. Seria bien, pregunto, poner la preparada con las gomas, para que hisiesse estos efetos? Claro está que no, por ser necessarios en tal occasion medicamentos, no que le enbotassen sus fuerças, sino que la corrigiessen, y juntamente la aiudassen a la penetracion, y a incidir los guessos humores. Sean testigos de esta verdad

Mes. y Galeno -- Melioramus (inquit Mes. cap. et Summa 1.) medicinarum operationes in permiscendo cum eis rem quae proprietate sua faciat virtutem earum pervenire ad membrum cuius materiam curare intendis. Galeno dise lo demas lib. quos quibus, etc. Cuias palabras son. danda autem opera est, ut quae miscentur semina sint extenuante atque incindente facultate quae lentos humores ita incidat, crassos extenuet, atque meatus per quos educendus est humor reseret ut non solum pharmacorum vim deleteriam corrigere, sed illorum etiam actionem adiuvare aptissime possit. Luego evidente conclusion, que ierran los que generalmente quieren, que en lugar dela Colocynthida se pongan sus trochiscos. Caeterum consulverim (dise Galeno lib. de the. ad Pisonem) singulis ipsis accurate exploratis medicamentum praepa-

rari, nam unius cuiusdem vitrium solamente poner en una Composition tan 
JOSÉ MARÍA VALDERAS

grande un simple mal escogido la corrompe, que haran estos trochiscos puestos en lugar dela Colocinthida, sino mudar las actiones alas medicinas en que se pusiere? fue recibida en el uso de la medicina sin preparar para ponerse en las Compositiones, no solamente la $\mathrm{Co}$ locimthida buena, sino tanbiem la mala, como paresce de Isaac cap.49 lib. 10: practicae, el qual entre otras hieras que escrivio puso una, intitulada hierafri, la qual dise que aprovecha para la epilepsia, y cephalia, y otras enfermedades, y pide en ella dela Colocinthida menor tres drachmas, y la que es pequeña reprueva Mesue, disiendo: Locus termarum Colocynthidas facit minores, et sunt similiter malae, y en pedirla pequenya

(22r) y sin preparar para esta Composition, no anduvo errado Isaac, sino mui acertado, pues, como queda dicho, de autoridad de hippocrates, Gal. et Paulo: Extremis morbis, extrema diligentissime remedia sunt adhibenda. A cuia causa no contentandosse con la Colocinthida mediana, por tener medianamente diffusa, ni con la grande, por tener mas difusa, y separada la substantia, pidió la menor por tenerla mas fuerte, y mas aggregada. Pues si la Colocinthida mala, y venenosa, se puede poner en las medicinas sin la particular preparation, por que no se podrá poner la salubre y buena? Y si tienen algunas medicinas necessidad de tanta actividad, como podran suplir por ella los dichos trochiscos. Es tanbien de notar, que no suplen las fuerças y actiones dela Colocinthida los trochiscos de

(22v) Alandahal, aunque se pongan en maior cantidad, y ansi no pueden ser recebidos por ella, porque seria mui mal suc- cedaneo. que tengan differentes actiones veese de fallopio, cap. 10: tract. de medic. purg. simp. donde dise que siendo los medicamentos catharticos corregidos se hazen semejantes a los lenitivos. tamen (inquit) si preparantur ita ut habeant imbecillem vim illam atractionem: vel si exhibeantur in minima quantitate, non purgabunt, sed lenient. Y compruevalo con autoridad de Paulo cap. 43. y de Oribasio, lib.8 Collec. cap. 41 et 42 , et 43 . Hasanse tanbien estos medicamentos, siendo erradicadivos minorativos. Como se vee del dicho fallopio, cap. 16 dicti tract. Y aun no solamente mudan las fuercas, pero tanbien el nombre, como se vera delos lugares citados de este Autor, y de Stephano

Ateniense in Comm. lib. 1 Gal. ad Glauconem. Ay un genero entre los medicamentos purgantes a quien llaman los Griegos $\alpha \lambda u \pi v$ o $\varsigma$ vel $u \pi \alpha \gamma$ o $\gamma$ ò $v$, vel $u \pi \alpha \lambda \alpha$ $\tau \sigma \mathrm{v}$, hoc est, subducens sine molestia, $\mathrm{y}$ tratando destos, el dicho Stephano, loco citato, dise Ypilata vocant Antiqui quae moderatas facere passunt evacuationes per alvum, ut polypodium, et mercurialis herba, Sed haec Simplicia sunt vero quaedam etiam Composita, ut nonnullae Confectiones, quibus injicit scammonium, et Colocynthis, et Agaricus, et Elaterium, y ser tan fuertes, y vehementes, dise, dise que se hasen ypilatos, que son moderados en la purgacion. de donde, y de todo lo demas referido en este discurso, se vee con evidencia que en haver puesto los trochiscos de Alandahal Cosme Novella en lugar dela Colocinthida, aunque aia sido en doblada cantidad

ha errado con ciega, y porfiada pertinacia, y que es digno de reprehension y castigo, y por el contrario deve ser honrado, y 
FRANCISCO VÉLEZ DE ARCINIEGA EN LA POLÉMICA DE LA COLOQUÍNTIDA

estimado el Colegio delos Medicos de Za-

ragoça, por aver puesto con tanto acier-

to en las Compositiones que piden colocin-

thida su pulpa sin Sosciedad, y en las

que piden trochiscos de Alhandal los

dichos trochiscos, dela propria manera

que lo quierren los autores Cujas son, y

este es mi parecer En. 2. de Enero de

1611--

Francisco Velez

de Arciniega-- 